\title{
Educação financeira e sustentabilidade na formação inicial dos futuros professores de matemática
}

\author{
Financial education and sustainability in the initial training of \\ future mathematics teachers
}

\author{
Patricia Franzoni ${ }^{1}$
}

Marli Teresinha Quartieri²

\section{Resumo}

Este artigo parte de uma pesquisa qualitativa e propõe-se a investigar as percepções dos licenciandos em Matemática de uma universidade no estado do Rio Grande do Sul sobre o tema educação financeira e suas relações com consumo consciente e sustentável. Foram utilizados filmagem do debate em sala de aula e fórum de discussões em ambiente virtual como instrumentos de coleta de dados. Os dados produzidos foram analisados mediante análise textual discursiva, surgindo duas categorias: a) consumo consciente e desenvolvimento do pensamento crítico; e b) educação financeira e sustentabilidade. Por meio deste estudo, conclui-se que a educação financeira está relacionada ao gerenciamento de renda, bem como ao consumo consciente e sustentável, de forma a aumentar a qualidade vida. $\mathrm{O}$ tema possibilitou discussões tanto em sala de aula como no fórum do ambiente virtual, fortalecendo o desenvolvimento do espírito crítico e os processos de ensino e de aprendizagem, contribuindo, dessa maneira, na

\footnotetext{
${ }^{1}$ Mestra em Economia (UFPB/ João Pessoa, PB, Brasil), Doutoranda em Ensino (UNIVATES, Lajeado, RS, Brasil), Bolsista da Coordenação de Aperfeiçoamento de Pessoal em Nivel Superior (CAPES), Professora de Economia (FURG, Rio Grande, RS, Brasil).

2 Doutora em Educação (UNISINOS, São Leopoldo, RS, Brasil), Bolsista de Produtividade de Pesquisa (CNPq - Nivel 2), Professora da Graduação em Matemática e Pós-Graduação (Mestrado e Doutorado em Ensino e Mestrado e Doutorado em Ensino de Ciências Exatas UNIVATES, Lajeado, RS, Brasil).

Interfaces da Educ., Paranaíba, v.11, n.32, p. 188 - 212, 2020
} 
formação inicial dos futuros professores da educação básica e/ou ensino superior.

Palavras-chave: Educação financeira. Consumo consciente. Ensino. Formação inicial.

\begin{abstract}
This article follows a qualitative research and aims to investigate the Math graduates' perceptions from a Rio Grande do Sul University about the topic financial education and its relations to conscious and sustainable consumption. Classroom debate recording/footage and virtual forum discussions were used as data collection tools. The data produced were analyzed through discursive textual analysis, with the rising of two categories: a) conscious consumption and critical thinking development, and b) financial education and sustainability. Through this study, we conclude that financial education is related to the income management, as well as to conscious and sustainable consumption in such a way as to improve quality of life. The topic yielded discussions in the classroom as well as in the virtual forum, strengthening the critical thinking development and the teaching and learning processes, thus, contributing to the future basic and/or superior teachers' initial formation.
\end{abstract}

Keywords: Financial education. Conscious consumption. Teaching. Initial formation.

\title{
Introdução
}

O Banco Mundial, a Organização para a Cooperação e o Desenvolvimento Econômico e o Ministério da Educação, entre outros órgãos têm-se mobilizado para ensinar educação financeira em diversos países. Dentre as justificativas estão: o aumento do número de produtos financeiros nos bancos, o aumento da expectativa de vida, as mudanças nos sistemas 
previdenciários, a falta de conhecimento de finanças, o endividamento das famílias e a recente crise financeira.

\begin{abstract}
A temática sobre a Educação Financeira faz parte da história recente de nosso país, pois em uma sociedade com sérios problemas ligados à estabilidade econômica torna-se praticamente impossivel realizar planejamentos futuros consolidados [...]. A partir de 1994, ano da implantação do Plano Real, passa-se a viver outro momento da história do Brasil, pois com a estabilização da economia e com o controle inflacionário, grande parte do povo brasileiro passou a ter acesso a uma série de situações que, até então, eram chamadas de "sonhos de consumo". Com o controle da inflação, com o acesso de um maior número de pessoas ao sistema bancário e a facilidade de obtenção de crédito criou um ambiente favorável ao crescimento do consumo do cidadão médio [...]. A partir dessa mudança de comportamento da sociedade brasileira, desenvolvem-se outras preocupações e novas demandas ligadas ao consumo em excesso e ao planejamento financeiro das pessoas e das famílias [...] (TEIXEIRA; KISTEMANN, 2017, p. 227-228).
\end{abstract}

Portanto, o consumismo em excesso, em função das facilidades na concessão de crédito, levou muitas famílias ao endividamento, aumentando a intervenção do Banco Central do Brasil tanto na economia para reduzir o consumo, como nas escolas para ensinar educação financeira. O tema educação financeira, no Brasil, está incluído na Base Nacional Comum Curricular (BNCC) e deve ser trabalhado de forma contextualizada e interdisciplinar na educação básica (BRASIL, 2016). Contudo, segundo Teixeira (2015), os conteúdos de Matemática Financeira estão sendo transmitidos aos alunos de maneira descontextualizada, existindo uma preocupação excessiva em ensinar por meio de fórmulas e tabelas, sem fazer referência ao cotidiano. É preciso unir teoria e prática, conectar o conhecimento técnico de fórmulas da Matemática Financeira com conteúdos da educação financeira (gerenciamento de renda, orçamento familiar, formas de investimento, planos de previdência, decisões de consumo), a fim de fazer melhores escolhas e solucionar problemas financeiros.

Se a compreensão do mundo econômico requer um indivíduo que construa uma visão sistêmica do modelo econômico social em que está inserido, a não compreensão desses modelos pode agravar os problemas sociais já existentes e criar outros como o endividamento ou superendividamento (DENEGRI et al., 2007, p. 49). 
Bauman (2008) comenta que o ser humano está vivendo na sociedade "líquido-moderna", na qual a felicidade está associada ao consumo excessivo e a rápida substituição de objetos. Essa busca incessante de felicidade associada a compra de novos objetos vem, de certa forma, tornando-se um problema para um número significativo da população, que acabou tornandose inadimplente.

Diante da problemática, o objetivo do presente estudo ${ }^{1}$, de abordagem qualitativa, foi investigar as percepções dos licenciandos em Matemática, de uma universidade no estado do Rio Grande do Sul, sobre o tema educação financeira e suas relações com consumo consciente e sustentável. A proposta da educação financeira nas salas de aula, segundo Santos, Menezes e Rodrigues (2016), nasce na expectativa de mudança de um cenário de consumo irresponsável pelo qual está passando a sociedade. A ideia é tornar os consumidores mais conscientes, capazes de tomar melhores decisões com relação ao consumo e à administração das finanças, que naturalmente impactará na qualidade de vida e sustentabilidade.

Para tanto, além desta introdução, a segunda seção refere-se à fundamentação teórica sobre educação financeira e formação inicial. Posteriormente, é apresentada a metodologia realizada para efetivar esta pesquisa. A quarta seção faz referência à análise dos dados, apresentando os principais resultados emergentes. Os dados produzidos foram analisados mediante análise textual discursiva, surgindo duas categorias: a) consumo consciente e desenvolvimento do pensamento crítico; e b) educação financeira e sustentabilidade. Por fim, a última seção explicita as conclusões deste estudo.

\section{Educação financeira na formação inicial}

A educação financeira está entre os temas da atualidade presentes na Base Nacional Comum Curricular (BNCC). Trata-se do conjunto de conhecimentos entendidos como essenciais para o fortalecimento da

\footnotetext{
${ }^{1}$ O presente trabalho foi realizado com apoio da Coordenação de Aperfeiçoamento de Pessoal de Nível Superior - Brasil (CAPES) - Código de Financiamento 001. Interfaces da Educ., Paranaíba, v.11, n.32, p. 188 - 212, 2020
} 
cidadania e voltados para ajudar a população a tomar decisões financeiras mais autônomas e conscientes (BRASIL, 2016). Denegri (1998) salienta que existe uma indiferença em introduzir conceitos econômicos no cotidiano das pessoas. Para a autora, nas familias não é comum os pais discutirem com os filhos seus problemas econômicos e a educação básica apresenta de forma muito superficial o consumo como tema transversal.

A definição de educação financeira, segundo o Banco Central do Brasil (2019, p. 1):

É o processo mediante o qual os indivíduos e as sociedades melhoram sua compreensão dos conceitos e produtos financeiros. Com informação, formação e orientação claras, as pessoas adquirem os valores e as competências necessárias para se tornarem conscientes das oportunidades e dos riscos a elas associados e, então, façam escolhas bem embasadas, saibam onde procurar ajuda e adotem outras ações que melhorem o seu bem-estar. Assim, a educação financeira é um processo que contribui, de modo consciente, para a formação de indivíduos e sociedades responsáveis, comprometidos com o futuro.

Nesse sentido, a educação financeira está associada ao gerenciamento da própria renda, decisões de consumo e investimento e ao orçamento doméstico, de modo que o indivíduo perceba a importância de ter conhecimento de educação financeira para utilizar de modo racional a sua renda.

A educação financeira tem sido um tema bastante discutido em nível nacional e principalmente internacional. Organismos representantes de diferentes países, autoridades governamentais tem manifestado interesse crescente acerca da necessidade dos cidadãos de adquirir conhecimentos que os ajudem na condução das suas finanças pessoais, além de auxiliá-los a orçar e gerir sua renda, bem como a poupar e investir (TEIXEIRA, 2015, p. 49).

O Banco Mundial, OCDE (Organização para a Cooperação e o Desenvolvimento Econômico) e o Ministério da Educação, entre outros órgãos, têm mostrado preocupação com o grau de endividamento das famílias. Para Kistemann (2011, p. 30), é fundamental ter conhecimento de educação financeira: "entendemos que a sociedade do século XXI não pode prescindir de discutir uma educação financeira, bem como significados em 
torno de ideias, que se embasam em práticas conscientes de consumo". Assim sendo, o ensino de educação financeira passou a fazer parte do currículo de diversas escolas do Brasil e exterior.

\begin{abstract}
No Brasil, temas como orçamento doméstico, poupança, aposentadoria, seguros e financiamentos passam a fazer parte do ambiente escolar. O Governo, em conjunto com o Ministério da Educação e com representantes da iniciativa privada e pública, elencou um conjunto de procedimentos, focados na contextualização do ensino, de forma que os alunos desenvolvam competências para sua inserção na vida adulta, mediante a multidisciplinaridade, o incentivo ao raciocinio e a capacidade de aprender (VARGAS, 2012, p. 59).
\end{abstract}

Nessa perspectiva, segundo o Banco Central do Brasil (2015), o acesso ao conhecimento de educação financeira possibilita ao indivíduo o desenvolvimento de valores e competências necessárias para se tornarem mais conscientes das oportunidades e riscos neles envolvidos. De modo geral, significa que a educação financeira pode ajudar as pessoas nas escolhas e a serem responsáveis sobre o planejamento das finanças pessoais.

Diante desse cenário, é importante problematizar e discutir conteúdos relacionados à educação financeira na formação inicial, para que os futuros professores se sintam mais preparados para ensinar, posteriormente, os seus alunos. No entanto, entre os problemas na formação inicial dos licenciandos, apontados nas Diretrizes Curriculares Nacionais (BRASIL, 2015), estão o distanciamento entre o ensino na formação inicial e as necessidades da profissão docente, a falta de articulação entre teoria e prática, a não abordagem de conhecimentos voltados para o uso das TIC (Tecnologias de Informação e Comunicação) na formação inicial, a necessidade de metodologias diferenciadas de ensino e contextualização curricular e a dificuldade dos alunos relacionadas à escrita e à argumentação. Tais problemas são considerados desafios contemporâneos que precisam ser solucionados. De acordo com Ponte (2002, p. 2-3), entre as competências para o exercício da docência que devem ser analisadas em cursos de formação inicial estão: 
A formação pessoal, social e cultural dos futuros docentes. Esta formação é, muitas vezes, completamente ignorada. Parte-se do principio que todo o estudante universitário teve oportunidade, pela sua formação escolar e não escolar anterior, de se desenvolver como pessoa e como cidadão o suficiente para poder vir a ser um bom professor, mas, na verdade, isso nem sempre acontece. A formação nestes campos pode favorecer o desenvolvimento de capacidades de reflexão, autonomia, cooperação e participação [...]. Em segundo lugar, surge, naturalmente, a formação científica, tecnológica, técnica ou artística na respectiva especialidade. Sem dominar, com um elevado grau de competência, os conteúdos que é suposto ensinar, o professor não pode exercer de modo adequado a sua função profissional [...]. É necessário que possua, ele próprio, competências significativas no domínio da análise crítica de situações e da produção de novo conhecimento visando a sua transformação.

Diante desse contexto, é importante proporcionar estudos sobre educação financeira na formação inicial, para que os futuros professores aprendam o conteúdo, desenvolvam, conforme exposto por Ponte (2002) e Brasil (2015), a argumentação, a capacidade de análise crítica e a própria escrita, tornando-se mais seguros para ensinar seus alunos.

\section{Metodologia}

Para alcançar o objetivo proposto, ou seja, investigar as percepções dos licenciandos em Matemática sobre o tema educação financeira e suas relações com consumo consciente e sustentável, a pesquisa foi realizada com uma turma de oito estudantes, do $6^{\circ}$ semestre, do curso de licenciatura em Matemática de uma universidade no Estado do Rio Grande do Sul, na disciplina de Matemática Financeira. Destaca-se que os oito estudantes, matriculados na disciplina, participaram deste estudo, que se caracteriza como uma pesquisa qualitativa. Esta, segundo Gerhardt e Silveira (2009, p. 31-32), "não se preocupa com representatividade numérica, mas com a compreensão de um grupo social, com aspectos da realidade que não podem ser quantificados, centrando-se na compreensão e explicação da dinâmica das relações sociais".

No primeiro dia de aula, com o propósito de investigar o perfil do aluno e o seu conhecimento sobre o tema, cada aluno precisou responder 
um questionário sobre finanças pessoais com perguntas sobre: consumo, investimentos, previdência, seguros, dívidas, organização financeira, economia, relações entre matemática financeira e educação financeira. Na sequência, os alunos foram orientados a elaborar uma planilha de orçamento doméstico pessoal. Para aqueles que nunca tinham feito um orçamento financeiro ou quisessem aperfeiçoar a sua planilha, foi solicitado que fizessem uma pesquisa sobre o assunto, porém cada aluno tinha a liberdade de escolher o modelo que achasse conveniente.

No final da aula, aconteceu o debate sobre educação financeira. Também foi aberto um tópico, no fórum do ambiente virtual da disciplina, sobre educação financeira para fomentar as discussões fora de sala de aula. Em tal ambiente, os alunos tiveram a possibilidade de refletir mais detalhadamente sobre o tema e estabelecer relações entre o orçamento financeiro produzido com consumo consciente e sustentável, proporcionando uma maior interação na turma. As considerações e comentários enriqueceram o aprendizado, desenvolveram a autonomia e o pensamento crítico dos alunos. Diante disso, destaca-se que os dados da pesquisa foram coletados por meio da filmagem do debate em sala de aula e discussões no fórum do ambiente virtual. As questões orientadoras durante o debate $\mathrm{e}$ fórum de discussão estavam relacionadas: 1) à diferença entre matemática financeira e educação financeira, 2) aos benefícios da realização do planejamento financeiro (orçamento doméstico), 3) às decisões de consumo e investimento, 4) à educação financeira na atualidade e a sua ligação com o meio ambiente, 5) à importância do conhecimento de economia no ensino de educação financeira e 6) ao desenvolvimento sustentável.

Nesse contexto, os dados emergentes foram analisados mediante a aplicação da ATD (Análise Textual Discursiva) que, conforme Moraes e Galiazzi (2016), configura-se como uma metodologia de etapas extremamente minuciosa, requerendo do pesquisador a atenção e a rigorosidade em cada etapa do processo. A ATD visa, inicialmente, à desmontagem dos textos e seu exame nos mínimos detalhes. $\mathrm{Na}$ sequência, desenvolve-se o estabelecimento de relações entre cada unidade, procurando-se a identidade Interfaces da Educ., Paranaíba, v.11, n.32, p. 188 - 212, 2020 
entre elas para, em seguida, captar o que emerge da totalidade do texto em direção a uma nova compreensão desse todo. Dessa forma, a ATD, de acordo com Moraes e Galiazzi (2016), é composta por três etapas, sendo a primeira delas o processo de unitarização, em que é desconstruído o texto, fragmentando-o em unidades de significado. O processo de unitarização é, portanto, a etapa essencial no desenvolvimento da ATD, pois nesta unidade estão contidas as mensagens mais significativas dos textos analisados. A segunda corresponde à organização de categorias, as quais podem ser constantemente reagrupadas. Por fim, na terceira, produz-se um metatexto com as novas compreensões obtidas.

Dessa forma, na primeira etapa os dados individuais transcritos do debate foram organizados, separadamente, em um quadro e cada coluna correspondia a uma questão orientadora na qual foram colocadas as palavras-chave a ela referentes. Após, foi realizado o mesmo procedimento para os dados individuais das postagens no fórum de discussão (Moodle). Na segunda etapa, foram estabelecidas as categorias para, na última etapa da ATD, produzir os metatextos por categoria, conectando o aporte teórico deste estudo às respostas dos alunos. Por questões éticas, não são divulgados os nomes dos participantes, identificados por: A1, A2 etc.

\section{Análise e resultados}

$\mathrm{Na}$ primeira fase deste estudo, os oito licenciandos em Matemática tiveram que responder um questionário sobre educação financeira e elaborar uma planilha de orçamento financeiro, com o objetivo de investigar os conhecimentos prévios a respeito do tema. Os dados demonstram que os licenciandos A5 e A6 não possuem conhecimento adequado sobre o tema:

Educação financeira é uma forma de aprender como transmitir, aos alunos, os conceitos da Matemática Financeira (A5).

A educação financeira faz parte da Matemática Financeira, lida com as fórmulas voltadas para o mercado econômico e conceitos relacionados a isso, como juros simples e juros compostos (A6). 
As respostas de A5 e A6 confirmam o resultado encontrado na pesquisa de Teixeira (2015), ao constatar que mais de $40 \%$ dos professores acreditam que Matemática Financeira é a mesma coisa que educação financeira. O que é frustrante neste estudo é que se trata de professores de Matemática Financeira.

Ainda, segundo Teixeira (2015), a Matemática Financeira é uma ferramenta necessária para se ensinar educação financeira e alcançar o letramento financeiro. No entanto, o conceito de educação financeira não se restringe apenas ao conhecimento de produtos financeiros, como ressaltado por A1:

A educação financeira trata do conhecimento dos produtos financeiros, presentes no dia-a-dia de todos os cidadãos, que nos oferecem e não sabemos como calcular e escolher a melhor alternativa. Por isso, a Matemática Financeira é importante (A1).

Por fim, os dados demonstram que quatro licenciandos possuem conhecimento sobre a diferença entre educação financeira e Matemática Financeira, mas apenas um desses alunos conseguiu estabelecer relações com os temas economia e sustentabilidade, quando estava elaborando a sua planilha de orçamento financeiro. Cabe ressaltar que esse aluno é o único que tem o hábito de controlar seus gastos, mensalmente, a partir de planilha financeira.

De acordo com Franzoni, Del Pino e Oliveira (2018), os conceitos de economia utilizados no cotidiano estão vinculados aos conceitos matemáticos, que também estão vinculados a outros saberes. Dessa forma, ao se perceber um caráter interdisciplinar da ciência por excelência, interlocuções com outros campos de conhecimento são de fundamental importância. No entanto, os resultados da pesquisa de Denegri et al. (2014) sinalizaram a precária formação econômica no currículo educacional. Os autores propõem um modelo de educação econômica na formação inicial, para que os futuros professores aprendam economia, tornem-se mais críticos e possam ensinar, de fato, educação financeira. Sendo assim, existe a necessidade de incorporar nos processos de formação inicial de professores a aprendizagem de conceitos-chave de economia.

Interfaces da Educ., Paranaíba, v.11, n.32, p. 188 - 212, 2020 
Portanto, após o debate em sala de aula e discussão no ambiente virtual, os dados coletados das seis questões orientadoras (descritas na metodologia) foram agrupados em duas categorias, a saber: a) consumo consciente e desenvolvimento do pensamento crítico; e b) educação financeira e sustentabilidade. A primeira categoria está relacionada ao posicionamento crítico dos alunos nos processos de tomada de decisão, na importância da conexão da educação financeira com a matemática financeira e economia, de forma a solucionar problemas financeiros do cotidiano e se atingir um consumo consciente, evitando o endividamento. A segunda categoria demonstra que é necessário ter consciência ambiental, pois o conhecimento de educação financeira relaciona-se não apenas aos recursos financeiros próprios, mas também aos recursos naturais e à preservação do meio-ambiente, de forma a aumentar a qualidade de vida e não comprometer o futuro das próximas gerações.

A seguir, apresentam-se as categorias emergentes com declarações dos alunos, bem como a referida discussão e imbricação com alguns autores:

\section{a) Consumo consciente e desenvolvimento do pensamento crítico}

Lusardi e Mitchell (2014) concluem em sua pesquisa que o conhecimento financeiro tem implicações importantes para o bem-estar e a maioria das pessoas em todo mundo são consideradas analfabetas financeiramente. Kistemann Jr. (2011) enfatiza a necessidade de incluir educação financeira em todos os contextos de formação dos estudantes desde a educação elementar até o ensino superior [...].

Os alunos A1 e A2 complementam que o conhecimento de educação financeira está vinculado a outros saberes, ao considerarem que a educação financeira envolve tanto o conhecimento de Matemática Financeira, como de Economia para solucionar problemas financeiros do cotidiano:

A educação financeira compreende ter noção tanto de Matemática Financeira, como de Economia para enfrentar problemas do nosso cotidiano (A1). 
Educação financeira, não é somente saber das fórmulas da Matemática Financeira, envolve o conhecimento de planejamento financeiro, consumo e poupança, para as pessoas não se endividarem e viverem melhor (A2).

A resposta do aluno A2 sobre o tema de educação financeira vem ao encontro de Teixeira (2015) quando destaca que é preciso unir teoria e prática, objetivando conectar a disciplina de Matemática Financeira com o conteúdo de educação financeira. Ainda, segundo o autor, a Matemática Financeira trata do conhecimento de fórmulas, estuda o valor do dinheiro no tempo, enquanto a educação financeira está relacionada ao gerenciamento da renda, às decisões de consumo e de investimento, de forma a aumentar a qualidade de vida, como ressalta o aluno A2.

Além disso, de acordo com Kistemann Jr. (2011), existe a necessidade de proporcionar aos alunos estratégias que auxiliem na tomada de decisões e condução de situações cotidianas, e se posicionarem como indivíduos críticos. Isso pode ser observado nas falas de A5, A7 e A1 que seguem:

A educação financeira faz o indivíduo desenvolver o pensamento crítico nas tomadas de decisões e ter um aumento na qualidade de vida (A5).

O conhecimento de educação financeira contribui no processo de reflexão, nos tornamos mais críticos e conscientes dos nossos atos, com relação a problemas financeiros do cotidiano (A7).

É importante fazer um orçamento doméstico para que não haja consumo excessivo e prejuizo financeiro. Entretanto, analisando os gastos da minha família percebo que fazemos muitos gastos e poderiamos economizar em determinadas despesas fazendo com que minimize as contas. Penso que educação financeira é consumir conscientemente, é um modo de evitar despesas desnecessárias, porém eu acabo tornando-me um consumidor "irracional", porque acabo gastando com supérfluos, produtos sem utilidade, preciso ser mais critico e repensar sobre essa estrutura (A1).

Sendo assim, "a atitude crítica se faz necessária a todas as atividades cotidianas, a necessidade de qualidade de vida, pressupõe a realização de escolhas, que permita diferenciar o essencial do supérfluo" (SILVA, 2008, p. 238) como destaca também o aluno A1. Ulhôa et al. $(2008$, p. 2) complementam que "o cidadão deste século não pode ter o mesmo perfil de habilidades do século passado. Não pode mais ignorar o que se passa no mundo, necessita se inserir de maneira adequada no meio social". Portanto, 
o conhecimento adquirido torna-se mais amplo quando é possível estabelecer relações entre teoria e prática, perceber a ligação do conteúdo com outras ciências, como por exemplo, a Economia e a sua aplicação no cotidiano, como ressaltam os alunos A7, A1 e A2.

Chen e Volpe (1998) concluem em sua pesquisa que os alunos precisam melhorar seus conhecimentos de finanças pessoais e economia, pois sem conhecimento adequado cometerão erros no mundo real, a incompetência limitará a capacidade de tomar decisões financeiras.

Conforme Bauman (2008), ainda, verifica-se uma instabilidade dos desejos aliada a uma insaciabilidade das necessidades, pela consequente tendência ao consumo instantâneo, bem como a rápida obsolescência dos objetos consumidos. Esse ambiente é desfavorável ao planejamento, ao investimento e ao armazenamento de longo prazo. Baudrillard (2008, p. 6) ressalta que "os consumidores sabem muito bem o que não querem, porém não sabem e ainda não aprenderam o que desejar". Também, de acordo com o autor, alguns consumidores agem por impulso, querem ter quase tudo e em muitas quantidades, mas ao mesmo tempo não sabem se realmente há utilidade, porque desejam de fato o produto. Isso pode ser observado no excerto do aluno A1, anteriormente escrito.

Pode-se inferir ainda que o consumo em níveis adequados, sem exageros e de acordo com a necessidade (utilidade), é imprescindível para o bom funcionamento da economia. Segundo Bauman (2008), a questão é torná-lo uma prática ética, consciente e responsável, equilibrada com a poupança. Ainda de acordo com o autor, o consumo é tratado como um direito de todas as pessoas, pois indistintamente são estimuladas a consumir, independentemente de sua condição para tal.

Quanto ao entendimento de educação financeira, observa-se nas respostas dos alunos A1, A2, A5 e A7 que está relacionado ao consumo consciente, racional de sua renda, de forma a aumentar a qualidade de vida. A educação financeira engloba conhecimentos de Matemática Financeira e Economia, com o objetivo de resolver problemas financeiros do cotidiano. Aliado a isso, o pensamento crítico é imprescindivel no processo de tomada Interfaces da Educ., Paranaíba, v.11, n.32, p. 188 - 212, 2020 
de decisão, levando em consideração a relação custo-benefíción ${ }^{2}$, para que se tenha um aumento no bem-estar.

\title{
b) Educação financeira e sustentabilidade
}

Pinho e Vasconcellos (2006, p. 8) ressaltam que a "economia é uma ciência social que estuda a administração dos recursos escassos". De fato, as escolhas envolvem trade-offs ${ }^{3}$, nada é grátis, ter mais de algo significa abrir mão de outra coisa, ou seja, "optar por gastar mais em alguma coisa nos deixa com menos para gastar em outra" (STIGLITZ; WALSH, 2003, p. 13). As escolhas são importantes e envolvem trade-offs, em função da escassez dos recursos. Por isso, não podemos gastar mais do que o necessário, exatamente como ressalta o aluno A8, para que os recursos não se esgotem:

\begin{abstract}
Educação financeira está relacionada a não gastar mais do que o necessário, saber se organizar financeiramente para que não se esgote os recursos no futuro. $\mathrm{Na}$ minha casa, usamos só o necessário de água e procuramos não utilizar automóveis para nos deslocarmos, porém utilizamos muitas sacolas plásticas e produzimos muito lixo, e não temos o hábito de separar o lixo orgânico e reciclável. Tentamos poupar o máximo de luz (energia) possivel, costumamos comprar o básico, mas esse básico depois gera muito lixo prejudicando o meio ambiente (A8).
\end{abstract}

Portanto, o conjunto de possibilidades de consumo que um indivíduo tem é definido pela restrição orçamentária e pelo reconhecimento dos tradeoffs. Segundo Stiglitz e Walsh (2003, p. 17), "não é possível fugir das escolhas, porque os bens e serviços desejados e os recursos existentes são inevitavelmente escassos". A escassez, de acordo com Mankiw (2005), implica que os consumidores se deparam com trade-offs e devem fazer escolhas, agindo racionalmente, ou seja, os consumidores devem ponderar os custos e beneficios de cada possibilidade sempre que se deparam com um processo de tomada de decisão, como realça a aluna A4, quando estabelece relações da educação financeira com a economia:

\footnotetext{
${ }^{2}$ É preciso analisar o custo-benefício, ou seja, "comparar os custos com os benefícios que provavelmente resultarão do investimento. Deve-se escolher, entre as várias opções, aquela que apresenta a maior diferença positiva entre os benefícios e os custos" (SANDRONI, 2008, p. 216).

${ }^{3}$ Ato de escolher uma coisa em detrimento de outra (MANKIW, 2005).
}

Interfaces da Educ., Paranaíba, v.11, n.32, p. 188 - 212, 2020 
Educação financeira abrange mais a questão da consciência consumista, sustentabilidade, prevenções econômicas, análise dos custos e beneficios individuais e sociais para não cair em ciladas em situações do cotidiano (A4).

De acordo com Grando e Scolari (2016, p. 674), "ao pensar em educação financeira, deve-se ter em mente os vários aspectos que estão ligados ao tema, como ética e dinheiro, consumo consciente, altas taxas de produção de lixo, impacto ambiental, exercício de cidadania e sustentabilidade". Logo, é preciso educar as pessoas em prol de um consumo consciente e sustentável. Oliveira et al. (2016) complementam que a sustentabilidade nada mais é do que a relação harmoniosa do indivíduo com a sociedade e com a natureza, enquanto a ética é determinada pelo modo de agir em sociedade, atribui-se a uma maneira exemplar de viver, fundamentada em valores morais.

O aluno A8 também salienta que o consumo excessivo e irresponsável contribui para as altas taxas de produção do lixo, quando diz: "costumamos comprar o básico, mas esse básico depois gera muito lixo prejudicando o meio ambiente". Silva (2014, p. 36) complementa:

Ser um consumidor consciente é o mesmo que ser um cidadão melhor, mudando sua maneira de encarar os desafios atuais relacionados às nossas fontes de água potável e de energia, ao lixo produzido, às embalagens plásticas que destroem a natureza, à reciclagem, à redução dos níveis de gás carbônico na atmosfera, etc.

Sendo assim, é preciso, também, proteger o meio ambiente, ter um pensamento de altruísmo intergeracional e não ser egoísta com as próximas gerações. De acordo com Pinho e Vasconcellos (2006), as necessidades humanas são ilimitadas e os recursos, escassos. Ademais:

Muitas práticas que utilizamos na vida adulta foram aprendidas na infância, como não desperdiçar comida, cuidar dos objetos para que tenham uma maior durabilidade, dosar o uso da água para ajudar na economia familiar. Todas essas práticas são defendidas pela Educação Financeira como temas a serem explorados em sala de aula, permitindo, dessa forma, uma formação pautada na conscientização da melhor administração dos bens e dos recursos (SANTOS; MENEZES; RODRIGUES, 2016, p. 104). 
É necessário saber que as nossas escolhas podem gerar custo ou beneficio a outras pessoas, quer dizer, é preciso ter consciência dos nossos atos, refletir sobre as consequências e avaliar o que está estabelecido como moralmente correto. Varian (2016, p. 667) ressalta "que uma situação econômica envolve uma externalidade de consumo se um consumidor se preocupar com o consumo do outro agente".

Nesse sentido, o consumo desenfreado gera um custo social, desestabilizando a economia e o meio ambiente. No momento em que o indivíduo não se preocupa com o consumo da água, da energia e da quantidade de lixo, está gerando uma externalidade negativa (custo) a outras pessoas. Entretanto, se o indivíduo se preocupa com os recursos, economiza água e energia e contribui na reciclagem do lixo, conforme ressalta o aluno A6, está gerando uma externalidade positiva (benefício) a outras pessoas, contribuindo dessa forma para o meio-ambiente e desenvolvimento sustentável.

Após começar a morar sozinho, eu peguei certo hábito de separar o lixo na casa, comprar somente o que irei consumir e nada em excesso, a estrutura da casa foi modificada para não fazer muito gastos de energia e tive a oportunidade de arrumar algumas coisas que pudesse causar vazamento de água e assim tento não fazer desperdício de água também, à noite evito manter luz acesa na casa (A6).

Segundo Santos, Menezes e Rodrigues (2016, p. 109), muitas pessoas acabam adquirindo modelos mais avançados de celulares, computadores e televisores sem necessidade, como se os aparelhos antigos perdessem a utilidade, favorecendo o acúmulo de lixo tecnológico e a degradação do meio ambiente:

\begin{abstract}
As tecnologias avançam rapidamente, levando algumas pessoas a trocarem seus bens por mais comodismo e desempenho, perdendo a noção do que é realmente necessário ou supérfluo. Os lixos tecnológicos, como celulares, tablets, baterias, aumentam e, esgotam-se cada vez mais rápido as fontes de matéria prima. A preocupação neste caso tem uma perspectiva macro, pois impacta no meio ambiente e na qualidade de vida das próximas gerações.
\end{abstract}

Lipovetisky (1989, p. 208) acrescenta "na vida agorista dos cidadãos da era consumista o motivo da pressa é, em parte, o impulso de adquirir e 
juntar, não interessando de como isso será pago ou se será, mas o motivo mais premente que torna a pressa imperativa é a necessidade de descartar e substituir". O relato da aluna A4, a seguir, vem ao encontro de Santos, Menezes e Rodrigues (2016) e Lipovetisky (1989), ao se considerar consumista e estar sempre trocando de celular, relógio e comprando eletrodomésticos para a sua casa. Com a discussão realizada, percebeu que não tinha consciência ambiental:

Toda essa discussão me fez perceber o quanto sou consumista e não tenho o mínimo de preocupação com o meio ambiente, eu não consigo parar de comprar eletrodomésticos, relógios, quando inventam um celular com uma tecnologia mais avançada já descarto o antigo, tenho um armário cheio de aparelhos velhos que não uso mais, muita coisa acaba indo para o lixo (A4).

A aluna A4 ressalta que a discussão realizada sobre educação financeira a fez perceber o quanto o assunto está relacionado ao consumo e ao meio ambiente. De acordo com Lipovetisky (2007, p. 21), "na sociedade do consumo, inaugura-se uma sociedade do desejo, onde o progresso e a felicidade são cada vez mais associados à melhoria das condições de vida e à aquisição de objetos de consumo". Nesse sentido, é necessário que o aluno tenha conhecimento de educação financeira com o objetivo de obter um consumo consciente e sustentável, mostrando preocupação, também, com o meio em que vive, contribuindo, dessa maneira, para o desenvolvimento econômico e sustentável do seu país.

Baudrillard (2008, p. 38) evidencia que "todas as sociedades desperdiçaram, gastaram e consumiram sempre além do estrito necessário. Sabe-se muito bem como a abundância das sociedades ricas está associada com o desperdício, ou seja, o supérfluo precede o necessário". A aluna A3 destaca que não costuma controlar o que gasta e descobriu, a partir das discussões e do orçamento doméstico produzido em aula, o quanto é necessário mudar alguns hábitos de consumo para reduzir custos, evitar o desperdício e agir de forma sustentável:

Não paramos em casa devido a correria diária, nossos gastos são feitos de modo desenfreado, não havendo um controle ou se quer planejamento, conforme vai surgindo às necessidades vai se gastando o que se tem. Isso é uma coisa que quero Interfaces da Educ., Paranaíba, v.11, n.32, p. 188 - 212, 2020 
mudar visto a tudo o que estamos discutindo e analisando e que me fizeram refletir muitas coisas que até então não paramos para pensar, fazer o orçamento me deu uma visão do todo, de mudar os hábitos de consumo, de reduzir custos e evitar o desperdício, de agir de forma consciente e sustentável (A3).

A partir da discussão realizada, observa-se que as justificativas para a defesa da importância de se educar financeiramente os alunos são diversas. Percebe-se, também, como a educação financeira não está relacionada apenas a fazer a melhor gestão do próprio dinheiro. Segundo os alunos desta pesquisa, para se adquirir conhecimento de educação financeira, é preciso entender de economia, compreender que o ensino de educação financeira não pode ser desenvolvido de forma isolada, desconectado do cotidiano, é preciso estabelecer relações entre teoria e prática, bem como fazer conexões com outras ciências, ao consumo consciente e a sustentabilidade financeira e ambiental. Ou seja, é necessário adquirir consciência de que o conhecimento de educação financeira está vinculado não somente a recursos financeiros, mas também aos recursos naturais e à degradação do meio-ambiente, em decorrência de um consumo irracional. O consumo, de acordo com Santos, Menezes e Rodrigues (2016, p. 106), não pode ser encarado como:

algo banal, rotineiro, sem planejamento e sem consequências, nem pode ser associado puramente à satisfação de nossas necessidades, ao prazer e a recompensas. Pelo contrário, deve ser responsável, planejado, estratégico, razoável, prudente.

Nesse cenário, o ensino de educação financeira é importante para que os alunos participem de maneira mais ativa na sociedade, desenvolvam o pensamento critico, reflitam sobre as suas escolhas e consequências individuais e coletivas dai advindas, atingindo dessa forma um consumo consciente e sustentável. Denegri et al. (1999) apud Silva (2008, p. 239) complementam esse raciocínio e apresentam quatro proposições que caracterizam um consumidor eficaz:

1) Um consumidor que tenha consciência de suas próprias necessidades dentro da sociedade de consumo em que vive. Conhece as características do mercado, sistemas de produção e Interfaces da Educ., Paranaíba, v.11, n.32, p. 188 - 212, 2020 
comercialização, conhece seus direitos e deveres de consumidor. Busca informações, é capaz de analisar, criticar e formar suas próprias ideias sobre o consumo. Desenvolve hábitos, e condutas de consumo que impliquem decisões racionais e equilibradas, evitando a impulsividade;

2) É capaz de compreender e interpretar o meio circundante. Possui conhecimentos básicos da economia e do mercado, bem como os recursos disponiveis e as implicações legais que regem esses fenômenos. Conhece os mecanismos de persuasão da publicidade e as formas de abordagem. Reconhece os fundamentos básicos do funcionamento do sistema ecológico e as estratégias de preservação do meio ambiente;

3) É atuante na sua comunidade quanto aos movimentos de consumidores que atuam junto aos poderes públicos e privados; participa ativamente dessas organizações, da formação, defesa e representação dessas entidades;

4) Reconhece as relações entre consumo e degradação ambiental. Seleciona os produtos de acordo com suas características de preservação do meio ambiente. Utiliza de forma racional os recursos energéticos não renováveis, participa de ações junto a instituições públicas e privadas a fim de conservar o meio ambiente saudável para as futuras gerações.

Portanto, é fundamental que o aluno aprenda educação financeira não somente para solucionar os seus problemas financeiros, mas também para compreender os problemas econômicos, sociais e ambientais vivenciados no seu cotidiano, mostrando preocupação em resolvê-los, lutando pelos seus direitos e cumprindo com seus deveres, contribuindo dessa forma para o aumento da qualidade de vida e o desenvolvimento econômico e sustentável do seu país e do mundo como um todo.

\section{Conclusão}

Este estudo teve o propósito de investigar as percepções dos licenciandos em Matemática, de uma universidade no estado do Rio Grande do Sul, sobre o tema educação financeira e suas relações com consumo consciente e sustentável.

Os dados da primeira etapa da pesquisa (conhecimentos prévios) demonstram que existe dificuldade por parte de alguns alunos em definir educação financeira e compreender a diferença entre esta e a Matemática Financeira, tendo um aluno inclusive deixado a questão em branco, sob a justificativa de não saber responder. Foi constatado, também, que a maioria dos licenciandos não conseguiu estabelecer relações da educação financeira Interfaces da Educ., Paranaíba, v.11, n.32, p. 188 - 212, 2020 
com os temas economia, consumo consciente e sustentabilidade, sendo que apenas um aluno obteve êxito na conexão, talvez por ter o costume de controlar as suas despesas, através da elaboração de planilha de orçamento pessoal, mensalmente.

Como discutido anteriormente, a falta de entendimento de educação financeira é considerada uma barreira para o aumento do bem-estar tanto individual como coletivo e, de acordo com o resultado das pesquisas mencionadas neste estudo, o conhecimento financeiro da maioria das pessoas não é adequado e precisa ser solucionado.

Com a análise dos dados do debate em sala de aula e discussões no ambiente virtual, a partir da Análise Textual Discursiva (ATD), foi possível atingir o objetivo proposto, ficando evidente a ampliação do conhecimento de educação financeira dos licenciandos em Matemática. Os dados foram agrupados em duas categorias: a) consumo consciente e desenvolvimento do pensamento crítico; e b) educação financeira e sustentabilidade. Os dados representativos dessas categorias demonstram que a educação financeira está relacionada ao gerenciamento da renda e ao consumo consciente e sustentável, de forma a aumentar a qualidade vida dos indivíduos.

Destaca-se, outrossim, que a educação financeira vai muito além do entendimento de fórmulas da Matemática Financeira como vimos anteriormente, a partir dos comentários dos alunos. Nesse contexto, é importante problematizar, discutir conteúdos de educação financeira e relacioná-los com a Matemática Financeira, economia e sustentabilidade na formação inicial dos licenciandos, em que todos sintam prazer em aprender, bem ainda sejam capazes de argumentar e desenvolver o senso crítico, em si próprios e também nos seus futuros alunos.

Por fim, cabe ressaltar que ao longo da pesquisa os alunos ficaram entusiasmados ao questionar, levantar hipóteses, participar do debate em sala de aula e no fórum, o que despertou as suas criatividade, autonomia e cooperação, basilares ao senso coletivo. A discussão realizada sobre educação financeira foi produtiva, fortalecendo o desenvolvimento do espírito crítico e os processos de ensino e de aprendizagem, contribuindo dessa Interfaces da Educ., Paranaíba, v.11, n.32, p. 188 - 212, 2020 
maneira na formação inicial dos futuros professores da educação básica e/ou superior.

Ademais, foi possivel constatar que o ensino de educação financeira possui reflexos diretos na formação da cidadania, na sustentabilidade do planeta e no desenvolvimento do poder de argumentação do aluno, ao refletir e ter consciência sobre as suas escolhas, atos e sobretudo as consequências nos processos decisórios relativos a situações-problema do cotidiano, tornando-se mais crítico, ético e comprometido com a sua nação e mundo.

\section{Referências}

BANCO CENTRAL DO BRASIL. O Banco Central e a educação financeira. 2019. Disponivel em:

https://www.bcb.gov.br/pre/bcuniversidade/introducaopef.asp. Acesso em: 27 de junho de 2019.

BANCO CENTRAL DO BRASIL. Brasil: implementando a estratégia nacional de educação financeira. 2015. Disponível em:

https://www.bcb.gov.br/pre/pef/port/Estrategia_Nacional_Educacao_Finan ceira_ENEF.pdf. Acesso em: 20 de junho de 2019.

BANCO MUNDIAL. Responsabilidade financeira. 2019. Disponível em: http://responsiblefinance.worldbank.org/publications/financial-capability. Acesso em: 12 de junho de 2019.

BAUDRILLARD, J. A sociedade de consumo. Lisboa: Edições 70, 2008. BAUMAN, Z. Vida para consumo: a transformação das pessoas em mercadoria. Rio de Janeiro: Zahar, 2008.

BRASIL. Estudantes aprenderão teoria e prática de finanças nas escolas. 2016. Ministério da Educação. Brasília. Disponivel em:

http:// portal.mec.gov.br. Consulta em: 20 de junho de 2019. 
BRASIL. Diretrizes curriculares nacionais para a formação inicial em nível superior (cursos de licenciatura, cursos de formação pedagógica para graduados e cursos de segunda licenciatura) e para a formação continuada. Resolução no 02/CP/CNE/2015 do Ministério da Educação. Conselho Nacional de Educação. Brasília, 2015.

CHEN, H.; VOLPE, R. P. An analysis of personal financial literacy among college students. Financial Services Review, Suécia, Orebro University, v. 7, n. 2, p. 107-128, 1998.

DENEGRI, M. La construcción de nociones econômicas em la infância y adolescência. Em: Jésus Ferro, José Amar (Ed.) Desarrollo Humano, Perspectiva Siglo XXI. Colombia: Edicciones Uninorte, 1998.

DENEGRI, M.; TORO, G. M.; LOPEZ, S. E. La comprensión del funcionamiento bancário en adolescentes chilenos: un estudio de psicología económica. Revista Interdisciplinaria, v. 24, n² 2, p. 137-159, 2007.

DENEGRI, M.; DEL VALLE, C.; GONZÁLEZ, Y.; ETCHEBARNE, S.; SEPÚLVEDA, J.; SANDOVAL, D. ¿Consumidores o ciudadanos? Una propuesta de inserción de la educación económica y financiera em la formación inicial docente. Estudios Pedagógicos, Chile, v. XI, n. 1, p. 75-96, 2014.

FRANZONI, P.; DEL PINO, J. C.; OLIVEIRA, E. C. Contribuições da economia para a alfabetização científica: uma proposta para a educação básica. Revista Contexto e Educação, ano 33, n. 105, p. 119-141, mai/ago. 2018.

GERHARDT, T. E.; SILVEIRA, D. T. Métodos de pesquisa. Porto Alegre: Editora da UFRGS, 2009. 
GRANDO, N. I.; SCOLARI, L. C. Educação financeira: uma proposta desenvolvida no ensino fundamental. Revista Educação, Matemática e Pesquisa, SP, v. 18, n. 2, p. 671-695, 2016.

KISTEMANN JR., M. A. Sobre a produção de significados e a tomada de decisão de indivíduos-consumidores. Tese de Doutorado em Educação Matemática. UNESP, SP, 2011.

LIPOVETSKY, G. A era do vazio: ensaio sobre o individualismo contemporâneo. Lisboa: Relógio d’água, 1989.

LIPOVETSKY, G. A felicidade paradoxal: ensaio sobre a sociedade de hiperconsumo. São Paulo: Companhia das Letras, 2007.

LUSARDI, A.; MITCHELL, O. The Economic Importance of Financial Literacy: Theory and Evidence. Journal of Economic Literature, Estados Unidos, v. 52, n. 1, p. 5-44, 2014. MANKIW, N. G. Introdução à Economia. São Paulo: Pioneira Thompson Learning, 2005.

MORAES, R.; GALIAZZI, M. do C. Análise textual discursiva. Ijuí: Unijuí, 2016.

OCDE - Organisation for Economic Cooperation and Development. OECD infe guidelines on financial education in schools. 2012. Disponivel em: https://www.oecd.org/daf/fin/financialeducation/2012\%20Schools\%20Guidelines.pdf. Acesso em 13 de julho de 2019.

OLIVEIRA, M. M. de.; MEDEIROS, M. H. A. da S.; SILVA, R. L. da; LUCAS, G. A. P. Desenvolvimento sustentável nas organizações como oportunidade de novos negócios. Revista Valore. Volta Redonda, v. 1 n. 1, p. 42-66, 2016. 
PINHO, B. P.; VASCONCELlOS, M. A. S. Manual de economia. $5^{\circ}$ edição. São Paulo: Saraiva, 2006.

PONTE, J. P. A vertente profissional da formação inicial de professores de matemática. Educação Matemática em Revista, no 11 A, 2002.

SANDRONI, P. Dicionário de Economia do Século XXI. Rio de Janeiro: Record, 2008.

SANTOS, B. C. M. dos; MENEZES, A. M. de C.; RODRIGUES, C. K. Finanças é assunto de criança? Uma proposta de educação financeira nos anos iniciais. Revista BoEM, Joinville, v.4. n.7, p. 101-115, ago./dez. 2016.

SILVA, A. B. B. Mentes Consumistas. 1 ed. São Paulo: Globo, 2014.

SILVA, S. B. Alfabetização econômica, hábitos de consumo e atitudes em direção ao endividamento de estudantes do curso de pedagogia. Tese de doutorado. Faculdade de Educação da Unicamp. Campinas, 2008.

STIGLITZ, J. E.; WALSH, C. E. Introdução à microeconomia. Rio de Janeiro: Campus, 2003.

TEIXEIRA, J. Um estudo diagnóstico sobre a percepção da relação entre educação financeira e matemática financeira. Tese de Doutorado em Educação Matemática. PUC/SP, São Paulo, 2015.

TEIXEIRA, W. C.; KISTEMANN JR., M. A. Uma investigação sobre a inserção da educação financeira em um curso de serviço de matemática financeira para graduandos de um curso de administração. Revista Educação, Matemática e Pesquisa, São Paulo, v. 19, n 1, p. 223-249, 2017. 
ULHÔA, E.; ARAÚJO, M. M.; ARAÚJO, V. N.; MOURA, D. G. A formação do aluno pesquisador. In: I Seminário Nacional de Educação Profissional e Tecnológica. Centro Federal de Educação Tecnológica de Minas Gerais CEFET, Minas Gerais, 2008.

VARGAS, P. R. R. Um estudo sobre educação financeira e instituição escolar. Tese de Doutorado. UNISINOS, São Leopoldo, 2012.

VARIAN, H. R. Microeconomia: uma abordagem moderna. $9^{\circ}$ edição. Rio de Janeiro: Campus, 2016. 